Una sinfonía más útil que un martillo. Crónica del IV Encuentro Cultura y Ciudadanía: Educación, Mediación, Público-s.

Isabel Cebrián Zarranz, periodista

y gestora cultural (relatora) / 25 


\section{Una sinfonía más útil que un martillo. Crónica del IV Encuentro Cultura y Ciudadanía: Educación, Mediación, Público-s.}

\section{Isabel Cebrián Zarranz, periodista y gestora cultural (relatora)}

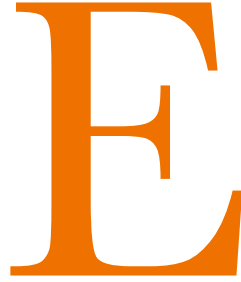

1 Encuentro Cultura y Ciudadanía, organizado por el Ministerio de Cultura y Deporte, se ha convertido en pocos años en un foro de referencia para reflexionar sobre diferentes aspectos de la teoría y la práctica de la Gestión Cultural y presentar proyectos que ponen en relación esos dos ejes. Su cuarta edición, celebrada en Madrid los días 3 y 4 de octubre de 2018 bajo el lema Educación, Mediación y Público-s, reunió a profesionales de la cultura de todo el país con una gran variedad de procedencias debido, sobre todo, a un gran trabajo de recogida de experiencias diversas y descentralizadas en el territorio seleccionadas por un comité académico formado por Benito Burgos Barrantes, Rafael Sanz, Leire San Martín, Alfredo Miralles, Zoe López Mediero, Javier Valbuena, Pepe Zapata, Laia Colell, Nuria Aidelman y Alberto Soler Soto. Fueron los encargados de dar forma a un programa dedicado a abordar de forma transversal y en muy diferentes artes y disciplinas una cuestión muy presente ya en encuentros previos: la dimensión educativa de la actividad cultural artística y su indisoluble relación con la participación y la construcción de públicos.

El centro cultural madrileño Daóiz y Velarde acogió dos completos días de conferencias, mesas redondas, pre- sentaciones de experiencias y talleres. Una gran variedad formatos y temas que, por horario y por extensión eran inabarcables para una sola persona y para una sola cronista: por suerte, el encuentro quedará registrado en un archivo audiovisual y contó con un espacio de co-escritura del Libro Blanco de la creación, formación y desarrollo de públicos en el que se volcarán las ideas de los y las profesionales que se reunieron en Madrid para el encuentro. Así, podemos dedicar esta crónica a perseguir por las diferentes mesas la respuesta a una pregunta que es la necesaria continuación de este encuentro: ¿qué significa participar en cultura?

\section{¿Para qué sirve visitar el Museo del Prado?}

La elección de la conferencia de apertura fue toda una declaración de intenciones. Nuncio Ordine, profesor de literatura italiana en la Universidad de Calabria -y bien conocido por su obra La utilidad de lo inútil. Manifiesto, hizo de su conferencia Alianza entre cultura, artes y educación: dimensión social y politica una oda a la cultura que trasciende el aula y una constatación de su preocupación por el abandono de la educación humanística en favor de los saberes utilitaristas. Asistimos, dijo el profesor italiano, a la transformación de la universidad en un espacio guiado por las lógicas de la pro- 




ductividad y el mercado, cuando son precisamente la cultura y el saber de las pocas cosas que desafían a las leyes de la escasez que guían la economía capitalista: «el conocimiento se puede compartir sin que ninguna de las personas implicadas en el intercambio salga con menos: la cultura nos enriquece a todas», recordó Ordine.

Aun así, insistía Ordine, parece que el placer y el saber gratuitos no encuentran terreno en una sociedad dominada por el utilitarismo. «¿Para qué sirve leer poesía, estudiar griego, visitar el Museo del Prado? (...) Claramente, un martillo es más valioso que un cuadro, un cuchillo más valioso que una sinfonía... pero invertir en cultura es invertir en la dignidad del hombre, o, como dijo citando el discurso de la inauguración de la biblioteca de Fuente Vaqueros de Federico García Lorca, la cultura nos hace amar a los demás y hace a la humanidad más humana».

La referencia a la biblioteca popular nos pareció un ejemplo perfecto para representar a la mayoría de los proyec- tos que, durante dos días, pasaron por las diferentes mesas redondas: es la de la biblioteca del pueblo una cultura que sale a buscar a la ciudadanía, que se presenta como herramienta, y no la cultura que espera sentada, en el interior del teatro, del museo, a que la ciudadanía la descubra y la admire en una vitrina.

\section{El público quién, el público dónde}

Pero precisamente es altamente problemático plantearse a dónde hay que salir a buscar a esa ciudadanía, cuáles son los espacios de la cultura hoy. O en palabras de Jesús Carrillo, profesor de Historia y Teoría del Arte y moderador de la mesa Público, públicos, agentes: qué-s, quiéne-s, cómo-s, porqué-s y para qué-s, las prácticas culturales más distribuidas, más participadas, son precisamente las menos canalizables e institucionalizables. Tal vez lo han sido siempre, o tal vez es el signo de nuestros tiempos. La intervención de Antonio Rodríguez de las Heras, catedrático de Humanidades en la Universidad Carlos III de 
Madrid, nos recordó que vivimos inmersos en «una impresionante transformación del mundo en red, tan impresionante que casi no la percibimos. Nos lo imaginamos como algo que se va extendiendo pero en realidad es una poderosa concentración, que nos lleva a una percepción distinta del espacio y el tiempo». Viviendo en un tiempo donde no existe la demora, donde estamos permanentemente traspasando el espejo, los espacios se diluyen. Preguntarse dónde está el público es tan baladí como preguntarse quién es el público, pues el público ya no es un sujeto único, sino móvil y caracterizado por unos determinadas rasgos que se reconstruyen de manera inmediata.

$\mathrm{Y}$ sin embargo, como gestoras no podemos dejar de preguntarnos quiénes están «en el lado oscuro de la sala», y es así como han surgido redes formales e informales de quienes trabajamos, desde las instituciones o de manera independiente, en la «formación de públicos», terreno que los teóricos y profesionales de América Latina han abonado con esmero. Desde Chile, Javier Ibacache Villalobos, crítico y programador de artes escénicas, desmenuzó clara y visualmente las categorías que nos permiten, hasta la fecha, comprender quiénes son los públicos, y nos introdujo en una conversación que, recordó, en Latinoamérica surge fundamentalmente desde la desigualdad social y va mucho más allá del acceso a la cultura, para situar al público en el centro de las prácticas culturales, con la complejidad que ello provoca.

Las experiencias presentadas en el trascurso del encuentro así pusieron de manifiesto esas tensiones, complejidades y la gran dimensión que tiene el término «participación». Una vertiente teórica para la que esta crónica - no llegamos a asistir al final de la mesa redonda en la que también intervenían Victoria Pérez Royo y Juan Antonio Álvarez Reyes- se queda corta. Por suerte, tenemos los libros.

\section{Una pausa para la lectura}

Y es que preferimos dedicar esta breve crónica a descubrir prácticas de participación en la multiplicidad de voces y experiencias que se presentaron en este encuentro y que no suelen tener voz en foros públicos, pues andan tejiendo redes y proyectos por todo el territorio. Antes de pasar a la Sala 2, donde se desarrollaron las mesas de experiencias, no olvidamos pasarnos por la pequeña biblioteca del encuentro, en la que el comité académico desplegó sus lecturas y referencias bibliográficas en un espacio en el que no faltaron ensayos como Rompiendo la quinta pared, de Eugene Carr, $\mathrm{Ni}$ arte ni educación, del Grupo de Educación de Matadero Madrid, La educación artística no son manualidades, de Lucía Acaso, Nueva ilustra- ción radical de Marina Garcés o El arte de la mediación de Oriol Fontdevilla, por citar algunos que llamaron nuestra atención.

$\mathrm{Y}$ ya que hablamos de libros, hay que nombrar la presencia de la iniciativa «Libros que importan», un inter-

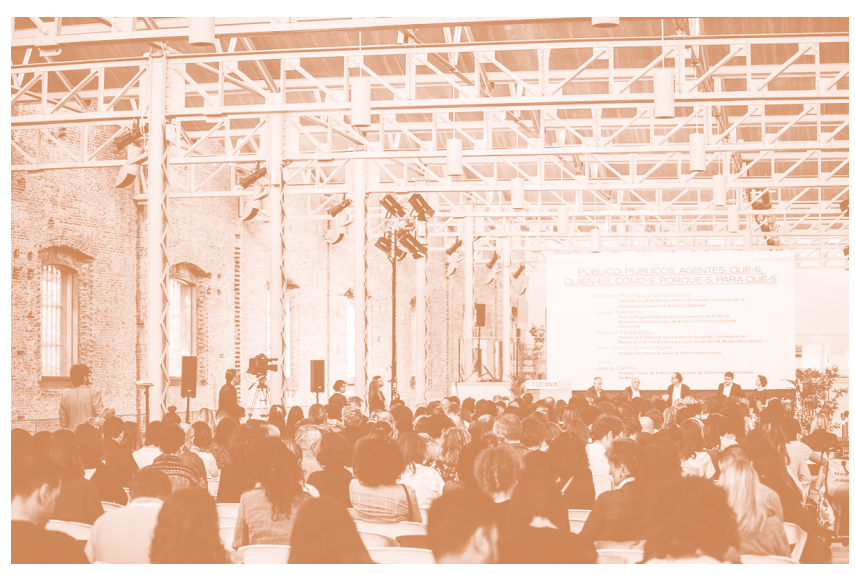

cambio masivo de libros en el espacio público que lleva dos años celebrándose en Zaragoza y tuvo una versión reducida en el contexto del encuentro. No fue la única «práctica situada» que pudimos ver los asistentes al encuentro: hubo intervenciones artísticas, espectáculos, paseos... entre las que destacamos el proyecto Antropoloops, un proyecto de collages musicales basados en la remezcla de músicas tradicionales del mundo, y que también tiene una pata educativa, y los paseos críticos de La Liminal, que nos llevó a conocer el entorno de Daoíz y Velarde los barrios de Pacífico y Adelfas de la mano de iniciativas vecinales.

Lo dicho, bajando a la práctica. Literalmente, porque era la Sala 2, en el sótano del edificio, la que acogió las mesas en las que se presentaron los proyectos seleccionados: un total de quince proyectos impulsados desde ayuntamientos, comunidades autónomas, mecenazgos o fundaciones privadas, también autogestionados, que desplegaron sus prácticas en una serie de mesas redondas donde llenamos libretas de notas y el tiempo siempre se quedaba corto para las rondas de preguntas.

\section{Mapeos y cartografías}

Es posible que la mediación y la educación artística sean para algunos todavía un territorio inexplorado - mu- 
chas siguen identificando «participación» con «asistencia» y «abierto» con «gratuito». Por eso, qué mejor que empezar trazando mapas. Le tocó abrir la mesa de Cartografías e Investigaciones a Andrea de Pascual, coordinadora de Pedagogías Invisibles, un colectivo fundado en 2009 que aborda la mediación desde la práctica, la formación y la investigación por cauces no formales. $\mathrm{Al}$ encuentro llegaron con una presentación sobre Cartografias de arte y educación social, el estado de la mediación en España, una investigación realizada en los últimos años y disponible online -cartografiasarteducadores. com. «Una investigación que busca saber reconocernos en otras e identificar formas de hacer que no gozan de tanta legitimidad pero que aportan su valor». A través de entrevistas y análisis de prácticas de agentes a nivel nacional, Pedagogías Invisibles ha acuñado el término de Arteducadora, un paraguas bajo el que se agrupan cada vez más profesionales que, según De Pascual, necesitan «más reconocimiento y nuevos imaginarios que permitan comprender esta figura a menudo desprestigiada, no reconocida y fuertemente atravesada por sus condiciones laborales». De ahí que Pedagogías Invisibles se hayan embarcado una nueva investigación o estudio, la «Foto fija sobre la situación de la mediación artística en el estado español», un proyecto que seguramente será material para próximos encuentros.

\section{El lujo de pararse, la necesidad de medir}

Condiciones de trabajo que en muchas ocasiones aceleran los procesos y convierten la posibilidad de pararse a reflexionar largamente sobre la propia práctica en un inmenso lujo. Lo sabe Isabelle Gallo, responsable para España de los proyectos de arte ciudadano de la Fundación Daniel y Nina Carasso. «Tuvimos la suerte como equipo de que nuestro patronato confiara en nosotras y nos regalara un año de pausa en nuestras convocatorias para poder pensar y profundizar en nuestra acción», explicó en su intervención, que giró en torno a la investigación que han realizado con los proyectos que durante los últimos años la fundación ha venido financiando. Con un formato de hackspace, la Fundación reunió el pasado mes de junio a estos proyectos en Medialab Prado para pensar y proponer en mesas de trabajo organizadas en torno a retos como la sostenibilidad de los proyectos, el modelo de intervención educativa, las necesidades de formación del profesorado y los contenidos y programaciones didácticas que se desarrollan. Gallo avanzó que los resultados y la hoja de ruta resultante de este encuentro, así como la metodología diseñada con el colectivo sevillano Zemos98, estarán disponibles a principios del año, pero apuntó dos reflexiones

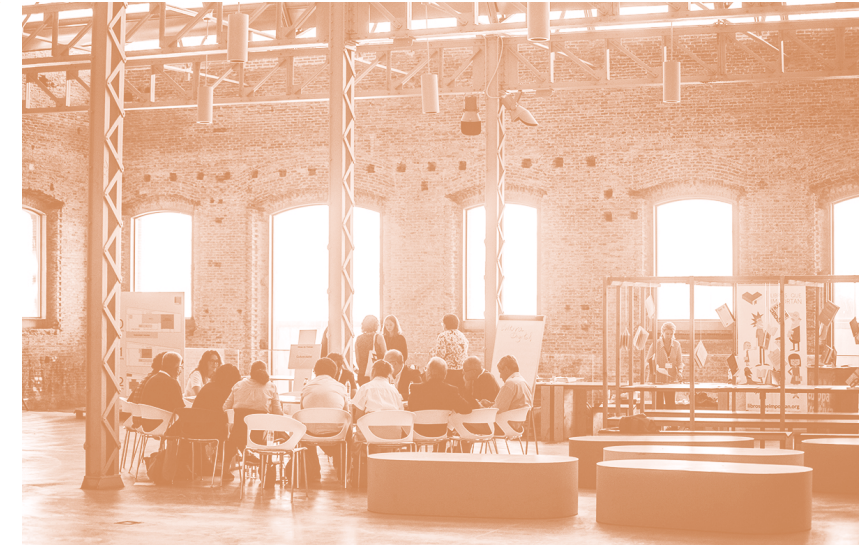

que flotarían después sobre todas las mesas del encuentro: el valor de intercambiar saberes y metodologías y, en definitiva, estar juntos y compartir espacios; y el hecho de que la relación cultura y ciudadanía siempre moviliza cuestiones éticas y que hay acciones necesarias que inapelablemente se tendrán que financiar desde lo público, el mecenazgo y con los valores de la economía social y solidaria.

De la investigación cualitativa a la cuantitativa, Virginia Garde, del Ministerio de Cultura y Deporte, fue la persona encargada de representar al proyecto permanente de investigación «Laboratorio Permanente de Público en Museos», un organismo encargado de conocer para quién programan «Nuestros museos». Es así como se conoce a un grupo de museos estatales repartidos en diferentes ciudades españolas que dependen de la Dirección General de Bellas Artes del Ministerio de Cultura y Deporte. Garde recordó todo lo que nos permiten saber los números. A saber: quién nos visita, quién no nos visita y en consecuencia, actuar con acciones muy concretas que tienen su especial reflejo en la comunicación. En el caso de estos museos, con un rediseño del sistema de folletos de mano, un plan denominado «Museos más sociales» y, lo que para Garde es un hito, el reconocimiento de esta necesidad de medir y evaluar en el Real Decreto que regula la actividad de los museos de la dirección general. Es ley. Garde cerró su intervención recordando a la audiencia que los datos son importantes, pero lo más importante es contar con quienes pueden convertir esos datos en conocimiento.

\section{Los datos como espejo, datos para la acción}

Representa bien esa transformación de los datos en acciones el plan de desarrollo de audiencias de Zaragoza 
es Cultura. Impulsado por el Área de Cultura del Ayuntamiento de Zaragoza dentro del proyecto europeo Adeste, representa todo un cambio estratégico en la forma en la que esta área trata los datos que obtiene de las compras de entradas, encuestas de satisfacción y otras acciones de comunicación y marketing. Ejemplo paradigmático de esto ha sido el plan de audiencias para el Auditorio de Zaragoza, al que el consistorio ha conseguido dar un giro en su venta de entradas y frenar la caída de venta de abonos reorientando la programación. Un feedback muy directo de la audiencia a través del personal de sala que ha permitido también cambiar horarios, sistemas de entradas o implantar una serie de acciones de comunicación que acompañan la experiencia del concierto antes de llegar a la sala y al regresar a casa. Los datos se han convertido en conocimiento y el conocimiento en acciones.

En la misma línea nos llevó el taller impartido por Teknecultura, a cargo de Ferrán López, miembro de esta consultora dedicada a analizar los datos de las grandes organizaciones culturales y a usarlos para fidelizar audiencias y captar nuevos públicos. Con las artes escénicas como principal campo de actuación de su empresa, López dio en su taller varias claves fácilmente escalables y aplicables a otros

Preguntarse dónde está

el público es tan baladí

como preguntarse quién

es el público, pues el público

ya no es un sujeto único,

sino móvil y caracterizado

por unos determinados

rasgos que se reconstruyen

de manera inmediata. ámbitos: todas las instituciones culturales tienen datos a su disposición, aunque estemos al principio del uso de los datos porque somos organizaciones pequeñas; al mirar a la audiencia tenemos que mirar a nuestros clientes y espectadores, pero también a las comunidades digitales; y evaluar el impacto de nuestro trabajo es igual de importante para «aquellos que pagan la fiesta»-financiadores, patrocinadores-como para nuestro público más fiel; y que, al final, es la comunidad de la que obtenemos los datos la que se beneficia de nuestra interpretación de los mismos. Son muchas las cosas que podemos saber de nuestro público, y si se lo pedimos amablemente la mayoría estará dispuesta a entablar ese diálogo en forma de intercambio de datos para que les demos un servicio mejor.

Pero decíamos que íbamos a hablar de participación y hemos terminado de nuevo en los usuarios. Es fácil perderse. Por eso Alberto Soler, gestor cultural y moderador de la mesa Agenciamiento, apropiación y participación, nos quiso recordar que «está en nosotros romper esa barrera y así demostrar que la cultura mana desde la participación - no una participación entendida como el número de gente que viene a nuestras actividades. La participación exige formar parte de las decisiones, no ser un receptor sino una pieza más del engranaje que hace funcionar el hecho cultural».

\section{Cultura en la casa, cultura en la fábrica}

La moderada por Alberto Soler fue una de las más entretenidas del encuentro. Pero cómo no serlo si una mesa redonda de un congreso comienza con un cuentacuentos del brillante Félix Albo, que encarnó uno de los lemas de su proyecto Pipiripao: que los planes de instigación lectora pasan por llevar la lectura a los lugares más insospechados. De su proyecto de desarrollo de la lectura y la creatividad en el ámbito familiar, que tiene como cómplices a bibliotecas y centros educativos por todo el Estado, aprendimos que se trata más de integrar la lectura (y por extensión, podríamos decir, la cultura) en todas partes, hacerlo una experiencia colectiva, incorporada en nuestro entorno - en este caso, en la familiay generar un vínculo especial con los lugares en los que se alberga la cultura. Como contrapunto hay proyectos como Libros a las fábricas, presentado por la Fundación Anastasio de Gracia, que optan por sacar la cultura de sus espacios más naturales. Pero es cuando la cultura se hace hogar, cuando se enraíza en el alma de quienes la participan, cuando podemos hablar realmente de agenciamiento y apropiación. Claramente Espiello, el festival internacional de documental etnográfico del Sobrarbe, es un buen ejemplo de una activi- 
dad cultural expandida, desarrollada en comunidad, con la población como agente que programa, produce y asiste a las actividades y que tiene numerosos efectos sobre el territorio, desde los económicos hasta las sociales y culturales.

\section{Que te inviten a la fiesta y que te saquen a bailar}

Durante el encuentro, alguien tuiteaba oportunamente la frase que se ha hecho popular y que creo hay que atribuirle a Vernā Myer: «diversidad es que te inviten a la fiesta, inclusión es que te saquen a bailar». Y a medio camino entre la diversidad y la inclusión está la integración: el campo de trabajo de Apropa Cultura. Su portal web, dedicado a la inclusión social, se propuso hace ya doce años hacer más accesibles actividades culturales en toda Cataluña teniendo en cuenta las características de cada actividad y espectáculo y las necesidades y capacidades de las diferentes comunidades y entidades que utilizan el portal para acceder a la información sobre las actividades de teatros, auditorios o museos. Apropa Cultura también trabaja para adaptar espectáculos o actividades a esas capacidades y necesidades. Su responsable, Sonia Gainza, señaló que el proyecto abre las puertas al «mundo sano» a personas con discapacidades, un espacio de socialización y salida de la rutina, y una oportunidad de, como dice uno de sus usuarios en el video con el que cerró la presentación, «sentimientos que si no accedes a la cultura no puedes experimentar». No es raro que donde más apoyo encontró el proyecto en sus inicios fuera en las entidades sociales, las primeras en creer en la cultura como herramienta de inserción social; Apropa ha conseguido evitar la barrera de la «caridad», «la carta del 'hola, por favor'», eliminando

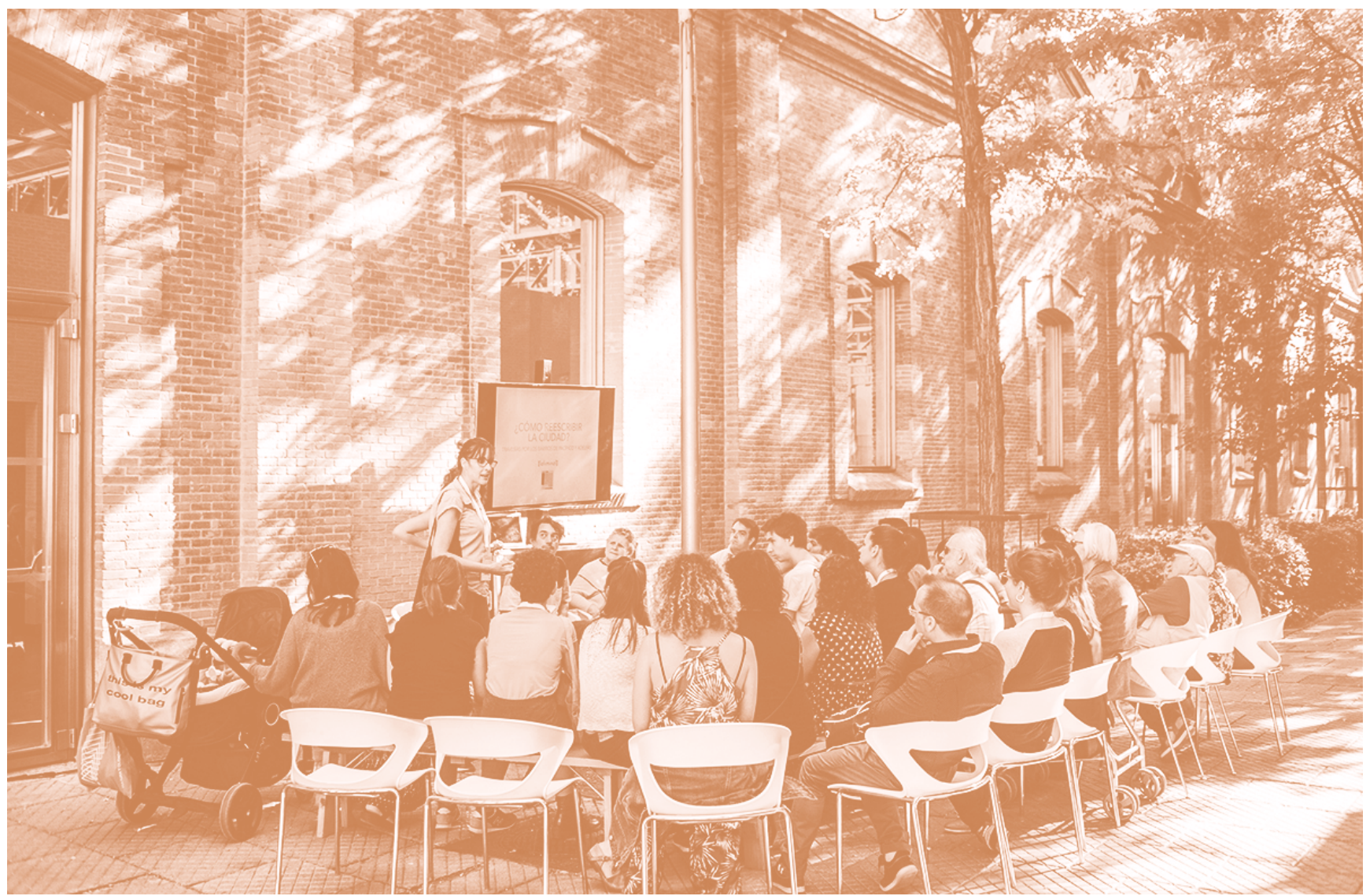


barreras económicas y tratando la cultura como un derecho, al menos en el acceso.

La cultura que tú quieres, en la puerta de tu casa: relatos desde el feminismo y la diversidad

Y del acceso a la acción: la mesa de feminismos dejó claro la necesidad de que los públicos diversos los sean solo de una manera expectante, y no activa. Herstoricas, por ejemplo, es un proyecto que visibiliza la historia de las mujeres y las genealogías feministas y organiza recorridos urbanos por diferentes ciudades -Madrid, Londres, Granada- y en museos. Reapropiándose del formato - la visita guiada-, han conseguido llevar a las salas de exposiciones el debate sobre cómo la cultura visual, las representaciones que encontramos en las pinacotecas, nos hablan de las sexualidades, de la violencia doméstica... y trabajando con otras mujeres para crear rutas que hablen de la historia de sí mismas.

$\mathrm{Y}$ es que contar la propia historia es una forma de genuino activismo cultural. Es lo que hace la Mostra La Ploma, un festival de cine en la ciudad de Valencia que tiene como objetivo erradicar la LGTBIfobia y acercar los lenguajes cinematográficos a los debates de su tiempo. Pero todavía más activo es contar la propia historia en los lugares en los que esta historia está ocurriendo: es lo que hace Agrocuir, un festival que nació con el objetivo de reivindicar la visibilidad de las identidades sexuales diversas en el contexto rural. Y por qué no, hacerlo de una manera que conecte con otras preocupaciones y luchas como el feminismo o la ecología, y hacerlo desde la cultura popular, con una fiesta con bailes, música o teatro que asemeja a la verbena popular. Integradora, diurna, participativa... y desde luego diversa.

\section{Lo que aprendemos de lo queer}

Seguramente eso es lo que podemos aprender de lo queer - la palabra que engloba a los géneros, cuerpos e iden- tidades sexuales no normativas: los publico-s con s al final, diversos, inaprensibles. Y desde una práctica cultural que atienda a esa diversidad podemos conseguir, como explicó el profesor y teórico de la intersección de transexualidad y educación, Lucas Platero, «desafiar la idea de un sujeto universal de la cultura». Una cultura que privilegia las experiencias y los saberes de una parte de la población, frecuentemente la blanca, la educada, la masculina o la heteronormativa, sin tener en cuenta a los sujetos diversos y las identidades múltiples. Platero volvió a poner una vez más el dedo en la llaga: cuando hablamos de participación, la cuestión está en la agencia o agenciamiento que se hace de los espacios de toma de decisiones, y nos invitó a repensar las relaciones de poder que forman parte de la producción del conocimiento. Un debate no exento de conflicto. Y sin embargo, dijo Platero, ¿por qué meternos en esos jardines? ¿Por qué llevar al aula el género, la sexualidad, la racialización, la diversidad funcional y corporal? «Porque la escuela nos socializa a todos», recordó.

Le tomó la palabra Belén Gopegui: «quien piense que aprender y enseñar son estatus que pertenecen a clases y edades diferentes va a perderse grandes cosas», coincidió la escritora. «La producción de sentido no es exclusiva de un grupo de personas, las divisiones persona que escribe/ persona que lee no son divisiones naturales (...) La educación no debería ser un instrumento de conformidad sino una herramienta para cuestionar lo dado, o al menos es lo que he visto en este foro». Así es como lo vimos también en esta crónica. La relación entre ciudadanía y cultura es fértil, y el eje arte-educación-públicos la hace crecer. Y encuentros como este dejan una sensación que la profesora Aida Sánchez resumió muy bien en su intervención: que abrir el código de las prácticas nos enriquece, y que por suerte es algo que cada vez hacemos más y a lo que espacios como este IV Encuentro de Cultura y Ciudadanía nos dan pie. 